\title{
Las finanzas concejiles y la fiscalidad de Nájera en la segunda mitad del siglo XV. El ejercicio del bolsero Martín Romero (1476-1477)
}

\author{
FCO. JAVIER GOICOLEA JULIÁN \\ Universidad del Pais Vasco
}

\section{INTRODUCCIÓN}

A lo largo de los últimos años el estudio de las haciendas municipales de las villas y ciudades medievales de la Corona de Castilla ha despertado el interés de un buen número de historiadores, experimentando un destacable crecimiento. De esta forma, en la mayor parte de las monografías dedicadas al estudio de núcleos urbanos, tanto de jurisdicción realenga como señorial, se suele reservar un capitulo al estudio de la hacienda concejil, y en algunos casos también a la incidencia de la fiscalidad proveniente de las instancias políticas superiores, monarquía y señorío, sobre la villa o ciudad objeto de estudio ${ }^{1}$. Igualmente se han

1 Sobre villas y ciudades de jurisdicción realenga pueden verse, entre otros, los estudios sobre Segovia (Maria ASEnjo González, Segovia, la ciudad y su tierra a fines del Medievo, Segovia, 1986, pp. 167-175), Ávila (José Ignacio Moreno Núnez, Ávila y su tierra en la Baja Edad Media (siglos XII-XV), Ávila, 1992, pp. 179-252), Zamora (Manuel Fernando LADERO QUESADA, La ciudad de Zamora en la época de los Reyes Católicos. Economía y gobierno, Zamora, 1991, pp. 199-257), Soria (Máximo Diago HERnANDo, Estructuras de poder en Soria a finales de la Edad Media, Valladolid, 1993, pp. 321-348), Trujillo (Carmen FERnÁndez-DAZA ALVEAR, La ciudad de Trujillo y su tierra en la Baja Edad Media, Madrid, 1991, pp. 494-565) o Cuenca (Yolanda Guerrero Navarrete y José María Sanchez Benito, Cuenca en la Baja Edad Media: un sistema de poder, Cuenca, 1994, pp. 205-235). Sobre villas y ciudades de jurisdicción señorial pueden verse, entre otros, los estudios sobre Benavente (Severino HERNÁNDEZ VICENTE, El concejo de Benavente en el siglo Xv, Zamora, 1986, pp. 185-205). Palencia (Asunción Esteban Recio, Palencia a fines de la Edad Media, Valladolid, 1989, pp. 90-102 y 136-146), Piedrahíta (Carmelo Luis LoPEZ, La comunidad de villa y tierra de Piedrahita en el tránsito de la Edad Media a la Moderna, Ávila, 1987, pp. 184-206 y 284-313), Alba de Tormes (José María Monsalvo ANTón, El sistema político concejii. El ejemplo del señorio medieval de Alba de Tormes y su concejo de villa y tierra, Salamanca, 1988, pp. 363-389) o Paredes de Nava (Juan Carlos MARTín CEA, El mundo rural castellano a 
realizado un buen número de estudios monográficos sobre diferentes aspectos fiscales de villas y ciudades en forma de artículos o de comunicaciones congresuales ${ }^{2}$, y últimamente se está prestando especial atención a determinados temas que habian sido descuidados por la historiografía, y que están relacionados con la política fiscal llevada a cabo por los concejos urbanos de la Corona de Castilla. Aspectos como los procesos recaudatorios utilizados o las políticas fiscales seguidas por determinados grupos sociales en algunas ciudades, han sido puestos de manifiesto en recientes trabajos ${ }^{3}$. Nuestro estudio, por tanto, pretende ser una pequeña contribución en este campo, y el inicio de una investigación más amplia con la que pretendemos dar a conocer las características de la fiscalidad concejil urbana en el territorio de La Rioja Alta ${ }^{4}$. Antes de iniciar el estudio conviene precisar el objetivo del mismo: dar a conocer las características de la hacienda concejil de Nájera en 1476-

fines de la Edad Media. El ejemplo de Paredes de Nava en el siglo xv, Valiadolid, 1991, pp. 223239.

Entre otros, sobre Murcia (Denis MENJOT, "Administración de las haciendas locales urbanas: El ejemplo de la ciudad de Murcia desde el año 1266 hasta mediados del siglo Xv", Historia de la Hacienda Española, épocas Antigua y Medieval, Madrid, 1982, pp. 447-483) e isabel Garcia DiEz, "La presión de la fiscalidad real sobre la ciudad de Murcia a finales del trescientos (1370-1390)", Hispania, vol. n. LXIX (1989), pp. 841-893), sobre Burgos (Julio A. PARDOS MARTinEZ, "La renta de alcabala vieja, portazgo y barra del Concejo de Burgos durante el siglo xv (1429-1503)", Historia de la Hacienda Española... o.c., pp. 607-680 y Yolanda Guerrero NAvARRETE, “Fiscalidad regia y poder municipal en Burgos (1453-1476)", En la España Medieval V (1986), pp. 481-500), sobre Madrid (Maria de los Ángeles Monturiol GonzÁlEZ, “El ingreso en la hacienda municipal de Madrid: su estructura y evolución (1464-1497)", Actas del Congreso: La Ciudad Hispánica durante los siglos XIII al xvI, Madrid, 1985, vol. n. $¹ 1$, pp. 1.027-1.057 y “Estructura y evolución del gasto en la Hacienda Municipal de Madrid: último tercio del siglo xv", En la España Medieval IV (1984), pp. 653-694), sobre Valladolid (Adeline Rucouol, "La enajenación de las rentas reales. El caso de Valladolid en los siglos XIII al XV", Historia de la Hacienda Española... o.c., pp. 799-823), sobre Segovia (Maria ASENJO GonZÁLEZ, "Repartimientos de "pechos" en Tierra de Segovia", Actas del Congreso: La Ciudad Hispánica... o.c., vol. n.․ 1, pp. 717-745), sobre Lequeitio (Ernesto GarcíA FERNÁNDE2, "Finanzas y fiscalidad de la villa de Lequeitio (1325-1516)", Anuario de Estudios Medievales, vol. n. 22 (1992), pp. 711-737), sobre Plasencia (Miguel Ángel LADERO QUESADA, "Rentas condales de Plasencia", El siglo xv en Castilla. Fuentes de renta y politica fiscal, Barcelona, 1982, pp. 168-190).

3 María Jesús FUENTE, "Sobre pechos y pecheros de un concejo medieval. Paredes de Nava", Espacio, Tiempo y Forma, Ha. Medieval, vol. n. 5 (1992), pp. 39-64, Adelina RoMERO MARTINEz, "Proceso recaudatorio y mecanismos fiscales en los concejos de la Corona de Castilla", Anuario de Estudios Medievales, vol. n. ${ }^{\circ} 22$ (1992), pp. 739-766, Francisco José ROMERo RoMERo, "El concejo como instrumento de la fiscalidad regia en la Castilla del siglo XV. Sevilla y los pedidos de cortes (1406-1474)", Actas del VI Coloquio Internacional de Historia Medieval de Andalucia, Málaga, 1991, pp. 161-166, Máximo Diago HeRnando, "La política fiscal del común de pecheros de Soria en el siglo XV y primeras décadas del XvI", Anuario de Estudios Medievales,vol. n. "22 (1992), pp. 821-852.

4 En mi Tesis Doctoral sobre Haro en el siglo xv he estudiado la hacienda concejil de esta villa. 
$1477^{5} \mathrm{y}$, así mismo, valorar el peso y la incidencia de las fiscalidades concejil, real y señorial sobre la ciudad de Nájera y sus aldeas en el trascurso de este ejercicio ${ }^{6}$.

La primera conclusión que sacamos al analizar el Libro de Cuentas de 1476-1477 7 , es que presenta una estructura formal muy similar, si no idéntica, a la de los Libros de Cuentas del concejo de la también villa altorriojana de Haro ${ }^{8}$. El Libro aparece estructurado en base a dos grandes capitulos: ingresos y gastos, dividiéndose a su vez el primer apartado en dos subapartados: ingresos en dinero e ingresos en "pan", es decir, en grano (trigo y cebada). Tanto los ingresos en dinero (maravedís) como los ingresos en grano (fanegas) figuran en letras en la zona central de cada folio, y en cifras romanas en la parte derecha. Igualmente, aunque no en todos los casos, también suele figurar en la parte izquierda de cada uno de los ingresos un resumen del mismo, identificándose con una única palabra que lo define. Un mecanismo que suponemos se utilizaría para agilizar la lectura y contabilidad de los ingresos del Libro. De la misma forma, en la zona inferior derecha de cada folio se escribe el monto de la suma parcial de los ingresos, situándose el monto global de éstos al final del Libro de Cuentas. En cuanto a los gastos, tanto en dinero como en grano, al igual que he podido comprobar para el caso de Haro, éstos se inscribian con una gran minuciosidad, detallándose el día y mes en que fueron realizados, y especificándose cada una de las expensas parciales en las que se dividía cada gasto. En efecto, cuando se inscribía el gasto acasionado por la concesión de un presente, no sólo se fijaba el costo total del presente, sino que también se añadia el valor de cada una de las viandas que

\footnotetext{
5 Más exactamente entre el 11 de noviembre de 1476, dia que inicia su ejercicio el bolsero Martin Romero, y el 11 de noviembre de 1477, día en que lo finaliza. El inicio y la finalización de los ejercicios de los bolseros del concejo de Nájera coincidía con el día de San Martin, en el mes de noviembre. Un estudio similar al nuestro aunque referido al siglo XIV y al reino de Valencia puede verse en (Antoni Furió y Ferrán GARCiA, "La economia municipal de Alzira a fines del siglo XIV según un libro de cuentas de 1380-1381", Actas del Congreso: La Ciudad Hispánica... o.c., vol. n.ำ Il, pp. 1611-1633).

- La ciudad de Nájera se encontraba en estos momentos en poder de Pedro Manrique, conde de Treviño. Según Rosa Maria Montero Tejada, Enrique IV le habia concedido Nájera en 1465 en recompensa por mantenerse fiel a su causa, frente al partido del Infante don Alfonso. En 1476 Fernando el Católico le confirmó el señorio sobre la ciudad, y en 1482 los Reyes Católicos le concederán el título de duque de Nájera (Rosa Maria MONTERo TEJADA, "Los señoríos de los Manrique en la Baja Edad Media", Espacio, Tiempo y Forma, vol. n.․․ 7 (1994), pp. 205-258, especialmente pp. 212 y 213).

7 Desde aqui quiero expresar mi agradecimiento al Ayuntamiento de Najera por las facilidades prestadas para la consulta de este documento.

8 Me remito a mi Tesis Doctoral.
} 
se concedian en el mismo ${ }^{9}$. Al igual que los ingresos, cada partida del gasto figura con letras en la zona central de cada folio y con cifras romanas en la margen derecha. También aquí se registran las sumas parciales, inscribiéndose la suma total de los gastos junto al total ingresado al finalizar el Libro de Cuentas ${ }^{10}$. Además de la exposición de los ingresos y de los gastos concejiles, en el Libro de Cuentas se insertan otros dos folios con interesante información adicional. En primer lugar el listado de los oficiales concejiles elegidos para el año de $1477^{11}$, listado que también constatamos en uno de los Libros de Cuentas del concejo de Haro ${ }^{12}$. En segundo lugar los montos pecuniarios obtenidos en los denominados «libros de cogechas", es decir, las cantidades de dinero recaudadas por los cogedores y que procedian de los "pechos" repartidos en la ciudad y en las aldeas de su alfoz para pagar los diferentes impuestos reales y señoriales. Información novedosa que no se registra en ninguno de los Libros de Cuentas del concejo de Haro consultados.

\section{LOS INGRESOS}

Antes de comenzar a analizar la estructura de la hacienda concejil conviene tener en cuenta que, tanto en el apartado de gastos como en el de ingresos, el bolsero del concejo anotaba los ingresos y gastos propiamente

9 En el presente que el concejo concedió a la condesa el 24 de diciembre de 1476, se especificaban los precios que habian costado 6 conejos, 6 pares de perdices, 10 pares de capones, 2 carneros, 1 pierna de vaca, 3 cántaras de vino blanco y 3 cántaras de vino tinto. La cuantia total del presente ascendió a 1.866 maravedis (A.M.N. (Archivo Municipal de Nájera): LC. (Libro de Cuentas) de 1476-77, cuenta de gastos).

10 Las cuentas del bolsero Martín Romero fueron revisadas el día 13 de noviembre de 1480 : "En la çibdat de Najera a trese dias del mes de nobienbre de mill e quatrocientos e ochenta annos en las casas que fase morada Garci Lopes de los Arcos, regidor, estando ende presentes el bachiller Ferrand Martines, alcalde, e Pero Sanches de San Biçente e Garci Lopes de Grannon e Juan Martines de San Miguel, regidores, e Diego Martines, contador, e Juan Manuel e Lapaya e Lope de Pania e el bachiller Alvar Gonçales e Juan Garçia e Juan Dias e Juan Manuel el moço e Diego Manuel e Ferrand Sanches, escribano, e otros asas buenos ommes de la çibdat ayuntados en su ayuntamiento de cámara resçibieron cuenta de Martín Romero que fue (bolsero) de la dicha çibdat el anno que pasó de mill e quatrosientos e setenta e siete annos..." (A.M.N: LC. 1476-77, cuenta de gastos, párrafo final).

11 Los oficiales concejiles eran elegidos el día de San Martín: "Estos son los ofiçiales sacados por el conçeio de la çibdad de Najera dia de Sant Martín de nobienbre anno de mill e quatrosientos e setenta e seis annos para el anno de I V CCCC LXX VII annos" (A.M.N.: LC. 1476-77, acta de elección de oficios, inserta al comienzo del Libro). Un corregidor desplazó a los dos alcaldes ordinarios en este año.

12 Concretamente en el primer Libro de Cuentas que se ha conservado en el Archivo Municipal de Haro, y que corresponde al año 1419. 
concejiles, asi como aquellas cuantías de maravedís derivadas de la fiscalidad extraconcejil (real y señorial) ${ }^{13}$. Para la presente investigación hemos considerado oportuno tener en cuenta de forma conjunta ambas fiscalidades, pues al conocer los montantes de los «libros de cogechas", disponemos de información sobre la cuantía de los repartimientos fiscales señoriales y reales recaudados en la jurisdicción de Nájera en este ejercicio, y porque además uno de los objetivos de la investigación es valorar, el peso jugado por ambas fiscalidades extraconcejiles en la ciudad de Nájera y en sus aldeas.

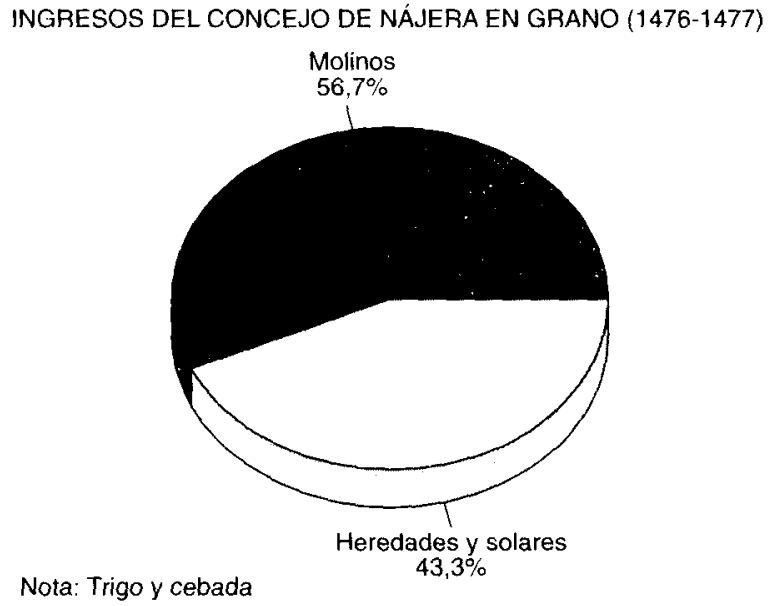

En lo referente a los ingresos en grano, trigo y cebada, el principal volumen procedía del arrendamiento de los bienes de propios, es decir, de los bienes inmuebles que el concejo poseía en el término jurisdiccional. La mayor parte del grano provenía de varios molinos propiedad del concejo, cuya renta era cobrada en trigo ${ }^{14}$. Le seguian las rentas provenientes del arrendamiento de varias heredades y solares que el concejo poseía dentro

13 El concejo se comportaba en este sentido como un gestor de la fiscalidad proveniente de las instancias políticas superiores. Sobre esta cuestión resultan de gran interés los trabajos ya citados de (José María MONSAlvo ANTÓN, El sistema político concejii.. o.c., pp. 377-389, Juan Carlos MARTIN CEA, El mundo rural castellano... o.c., pp. 234-239, María Jesús FUENTE, "Sobre pechos y pecheros de un concejo medieval... o.c., pp. 39-64 y Adelina Romero Martinez, “Proceso recaudatorio y mecanismos fiscales... o.c., pp. 739-766).

14 Aparecen como renteros de los molinos los molineros Martín de Soria y Juan de Acosta, 
de su jurisdicción, y que eran cobradas a partes iguales en trigo y cebada ${ }^{15}$. En porcentajes los ingresos de trigo supusieron en este ejercicio un $78,3 \%$ del total, frente al $21,6 \%$ de los ingresos de cebada.

En cuanto a los ingresos en dinero, éstos procedían de cinco fuentes principales: de los propios concejiles, de las penas impuestas en la ciudad y en su término, de los repartimientos fiscales concejiles, de los repartimientos fiscales extraconcejiles y de otros ingresos conformados por los «xeriques». Los propios concejiles constituian el principal recurso financiero del concejo con un $47,4 \%$ del total de los ingresos. Los ingresos de los propios procedian en primer lugar de varias rentas, en segundo lugar de la venta del grano proveniente de los molinos, solares y heredades concejiles, es decir, de la explotación de los bienes inmuebles del concejo, y en tercer lugar de la venta de propiedades inmuebles concejiles, concretamente de varios solares. Las rentas de propios estaban conformadas por una serie de derechos percibidos por el concejo, entre los que podemos distinguir los siguientes grupos:

\section{INGRESOS DEL CONCEJO DE NÁJERA EN DINERO (1476-1477)}

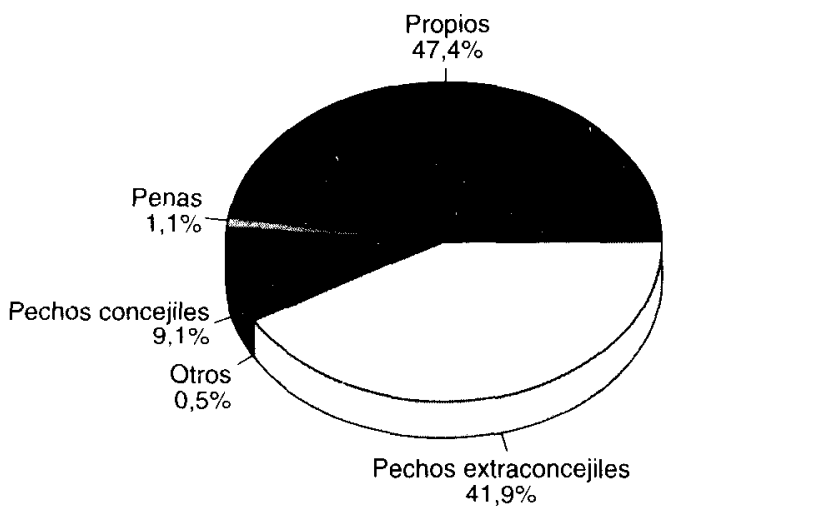

que pagan 220 fanegas de trigo de renta (A.M.N.: LC. 1476-77, cuenta de ingresos de "pan"). La explotación de molinos concejiles también está constatada en otros núcleos urbanos de la Rioja Alta como Logroño (Margarita CANTERA MONTENEGRO, "La organización concejil de Logroño en la Edad Media», en José Ángel Sesma MuÑoz (Coord.), Historia de la Ciudad de Logroño, Logroño, 1995, vol. n. 2 (Edad Media), pp. 463-491, especialmente p. 484) o Haro, donde el monto de trigo procedente de la explotación del molino concejil, osciló entre las 20 y las 60 fanegas a lo largo del siglo xv (me remito a mi Tesis Doctoral).

${ }_{15}$ En total 84 fanegas de trigo y otras tantas de cebada (A.M.N.: LC. 1476-77, cuenta de ingresos de "pan»). Los pagos en especie también estaban generalizados en núcleos urbanos cer- 
- Imposiciones sobre la realización de determinadas actividades liberales, artesanales y comerciales en la ciudad (rentas de la escribania, correduria, botica, aver del peso y sisa de la carniceria).

- Imposiciones sobre la realización de actividades cinegéticas (veda de la caza) y utilización de ríos y caminos (renta de los ríos y caminos).

- Imposiciones sobre el trasiego de viandantes por el puente (peaje del puente).

- Derechos percibidos por el arrendamiento de determinados oficios (juraderia, custierazgo de los valles y sobrecusteria de los valles).

- Derechos percibidos por la utilización de bienes del concejo (renta del trujal).

- Derechos percibidos por el arrendamiento de los ejidos y heredades concejiles en el término de la ciudad y en las aldeas (rentas de los ejidos, viñas de Cenicero, renta de matarredo y divisas de majarres,campos alvos, renta de Gallinero, herbaje de Alesón y renta de la parra) ${ }^{16}$.

- Imposición de tasas (tasa del limosnero del monasterio de Santa Maria, tasa del monasterio de Cañas y tasa de la abadía).

- Imposiciones sobre la población aldeana (derecho de los vecinos de Cenicero).

- Varios derechos cuyo contenido desconocemos (rentas de la portería, Najerilla, cuevas y palomas).

Todas estas rentas se explotaban en régimen de arrendamiento ${ }^{17}$, siendo las más cuantiosas en este ejercicio las rentas de Gallinero (cuatro mil quinientos maravedís), sisa de la carnicería (tres mil novecientos maravedís), Najerilla (tres mil setecientos cincuenta maravedís), la renta de los campos alvos (tres mil quinientos maravedís) y la renta del aver del

\footnotetext{
canos como Haro. El concejo de esta villa percibia la casi totalidad de las rentas procedentes de los bienes de propios rústicos, en especie, trigo sobre todo, y en menor medida cebada (me remito a mi Tesis Doctoral). Esta práctica también se daba en otros lugares bastante más alejados de Nájera. En Trujillo, parte del arrendamiento de las dehesas de propios concejiles se pagaba en especie, concretamente en fanegas de trigo (Carmen FeRnández-DAZA AlveAR, La ciudad de Trujilio y su tierra... o.c., pp. 496-499).

16 Podemos comprobar cómo el concejo de Nájera cobraba los arrendamientos de los bienes de propios tanto en especie (trigo y cebada) como en dinero.

17 "De la renta del trujal dos mill maravedis, rematose en el alcaide Juan de Salinas" (A.M.N.: LC. 1476-77, cuenta de ingresos en dinero). La explotación de las rentas concejiles mediante el arrendamiento de las mismas a particulares es una fórmula generalizada en la Corona de Castilla a tinales de la Edad Media. Me remito a la bibliografia de la nota $n . \stackrel{ }{ } 1$.
} 
peso (tres mil maravedís). En el otro extremo se encontraba la renta de la parra que proporcionó al concejo un maravedi ${ }^{18}$. Dentro de los ingresos procedentes de los propios, las rentas constituian la principal aportación a las arcas concejiles con un $25,6 \%$ del total de los ingresos ${ }^{19}$. Le seguian los maravedís obtenidos por las ventas de grano con un $20,6 \%$ del total de ingresos ${ }^{20}$, y a mucha mayor distancia los ingresos procedentes de las ventas de bienes inmuebles (solares concejiles) con un 1,2\% del total ${ }^{21}$. A los ingresos procedentes de los propios concejiles les seguian muy de cerca los ingresos provenientes de los "pechos" repartidos en la ciudad y en las aldeas para pagar los impuestos directos reales y señoriales. Estas imposiciones fueron el pedido, las monedas y la martiniega, que supusieron en el ejercicio $1476-1477$ un $41,9 \%$ del total de los maravedis recaudados por el bolsero Martín Romero. A una distancia bastante mayor se situaban los ingresos procedentes de los repartimientos fiscales concejiles (un $9,1 \%$ ), en concreto de un "pecho" repartido en la ciudad para reparar el puente ${ }^{22}$. Los ingresos procedentes de las penas del juego, de la botica, de las huertas y de Najerilla (un 1,1\% del total), y los ingresos procedentes de los "xeriques" de las vacas y de las ovejas (un $0,5 \%$ ) ocupaban los dos últimos lugares ${ }^{23}$.

1в Del ençense de la parra de Juan Peres un maravedi (A.M.N.: LC. 1476-77, cuenta de ingresos en dinero).

19 Esta misma situación se daba en Haro, aunque en esta villa los ingresos procedentes de las rentas de propios eran bastante superiores a los de Nájera. Así, en 1475, el concejo de Haro ingresó 86.586 maravedis por este concepto (el dato puede comprobarse en A.M.H (Archivo Municipal de Haro: LC. 1475, cuenta de ingresos en dinero, me remito a mi Tesis Doctoral), frente a los 30.191 maravedis ingresados por el concejo de Nájera.

20 En este ejercicio sólo se vendió trigo, en total 168 fanegas, por las que se obtuvieron 24.250 maravedis (A.M.N.: LC. 1476-77, cuenta de ingresos en dinero). En 1475 el concejo de Haro vendió 204,5 fanegas de trigo, de las que obtuvo 21.539 maravedis (me remito a mi Tesis Doctoral). Evidentemente, la diferencia se encuentra en el precio de venta de la fanega. En Haro el precio máximo alcanzado en 1475 fue de 84 maravedis, mientras que en Nájera en el ejercicio 1476-77 se alcanzó un precio máximo de 160 maravedis.

$21 \mathrm{El}$ concejo vendió 3 solares por los que obtuvo un total de 1.400 maravedis (A.M.N.: LC. 1476-77, cuenta de ingresos en dinero).

22 «Resçibí de la cogecha de la puente de Alvaro de Matute segund lo dio por cuenta a los regidores e paresçió por menudo dies mill e seisçientos e setenta e ocho maravedis" (A.M.N.: LC. 1476-77, cuenta de ingresos en dinero). El recurso de las haciendas concejiles a imposiciones de carácter extraordinario, repartimientos fiscales y sisas fundamentalmente, se generalizará a lo largo del siglo $X V$, muy especialmente durante el reinado de los Reyes Católicos. Así lo ponía de manifiesto Miguel Ángel LaDero QUESADA en un reciente Congreso (Miguel Ángel LADERo QueSADA, "Las haciendas concejiles en la Corona de Castilla (una visión de conjunto)", ponencia presentada en el $V$ Congreso de Estudios Medievales: "Finanzas y Fiscalidad Municipal", León, dias 2-6 de octubre de 1995).

23 En Haro, los montos pecuniarios procedentes de las penas jugaron también un papel poco importante en el conjunto de los ingresos concejiles. Concretamente un 3,2\% del total a lo largo 


\section{GASTOS DEL CONCEJO DE NÁJERA EN DINERO (1476-1477)}

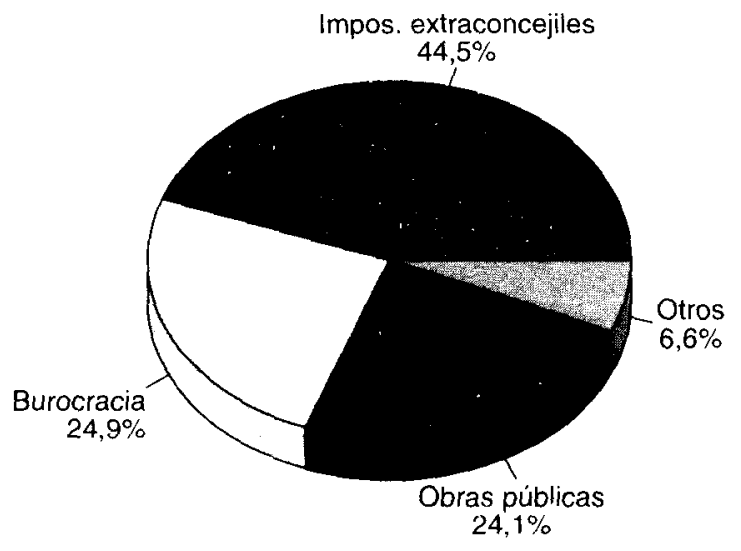

\section{LOS GASTOS}

En cuanto al gasto, los pagos efectuados en dinero por el bolsero Martín Romero en el ejercicio 1476-1477 tuvieron los siguientes destinos. En orden de importancia sobresalian los gastos extraconcejiles (un 44,5\% del total), conformados por varias cuantías de maravedís destinadas al pago del pedido, monedas, martiniega y alcabala ${ }^{24}$, por la concesión de presentes a los señores de la ciudad ${ }^{25}$, y por el pago de salarios a los peones y ballesteros que acudían en servicio del conde de Treviño ${ }^{26}$. Con

del siglo XV (me remito a mi Tesis Doctoral). Sin embargo, esto no fue una norma general en todos los concejos de la Corona de Castilla. Asi, en Paredes de Nava, los ingresos ordinarios procedentes de las penas y multas tuvieron un peso nada despreciable en el monto total de ingresos (Juan Carlos MARTiN CEA, El mundo rural castellano... o.c., pp. 232-233).

24 «Tengo pagados fasta oy a Garci Sanches alcabalero tres mill maravedis, más le di otros mill quinientos maravedis" (A.M.N.: LC. 1476-77, cuenta de gastos, pago efectuado el 1 de septiembre).

25 "Este dia (4 de abril) mandó la çibdad faser presente a la condesa que parió un fijo, costaron quatro cabritos tresientos maravedis...". En total el presente ascendió a 2.330 maravedis (A.M.N.: LC. 1476-77, cuenta de gastos). En el caso de los concejos de señorío, estos gastos llegaron a alcanzar unos índices nada despreciables. Asi lo he podido comprobar en el caso de Haro, señorio de los Fernández de Velasco durante la mayor parte del siglo XV (me remito a mi Tesis Doctoral). También lo ha constatado Carmelo LUIS LOPEZ para el caso de Piedrahita (Carmelo LuIS López, La comunidad de villa y tierra... o.c., pp. 304-313).

26 "A treinta días de março enbió el conde nuestro sennor por çinco ballesteros para inbiar a Balmaseda a costa de la çibdad, inviaron a Lope de Cortaçar e a Juan Çereso e a Santjuan e a Fernando de Santa Gadea e a otro de Triçio, mandaron les dar cada quinse reales". En total 
un $24,9 \%$ del total se situaban los gastos burocráticos, conformados por las costas ocasionadas por la compra de papel para los diferentes Libros del concejo, por las nóminas salariales de los oficiales del concejo (bolsero, procurador y pregonero), por los salarios pagados a profesionales contratados por el concejo (borrero o verdugo, campanero, letrado, físico doctor y bachiller de la gramática) ${ }^{27}$, y por los gastos ocasionados por el envío de mensajeros a las villas y ciudades comarcanas, así como a las cortes real y señorial. Le seguian los pagos efectuados para las obras públicas de la ciudad con un $24,1 \%$ del total. Gastos ocasionados por las reparaciones realizadas en la muralla, puertas de la ciudad, garitas, caramanchones, carnicería, puente y, sobre todo, en los molinos concejiles ${ }^{28}$. Por último, un 6,6\% del total se destinó este año al pago de diferentes costas que quedaban al margen de los otros apartados fundamentales del gasto. Sobresaliendo las devoluciones de dinero a oficiales y renteros del concejo, las costas ocasionadas con motivo de las comidas efectuadas por los oficiales concejiles y por representantes de las villas y ciudades comarcanas que acudian a Nájera, y la concesión de limosnas ${ }^{29}$.

2.250 maravedís (A.M.N.: LC. 1476-77, cuenta de gastos). Sorprende, sin embargo, que no aparezca asentada en el Libro la cuantía pecuniaria destinada al pago del salario del Corregidor.

${ }_{27}$ Los alcaldes y regidores, principales oficiales concejiles, no aparecen en nómina. Podemos deducir que la no comparecencia de los alcaldes se debe a la presencia del Corregidor. Sin embargo, el hecho de que ni los alcaldes ni los regidores aparezcan en nómina en el resto de los Libros de Cuentas conservados (años 1439-40 y 1455-56), nos lleva a plantear la hipótesis de que su salario podria estar contormado por la percepción de determinados derechos, y no por el pago de una cantidad fija de dinero. En lo referente a los profesionales contratados, la nómina más alta correspondia al físico doctor (4.500 maravedis, pago efectuado el 3 de septiembre) y la más baja al campanero (250 maravedís, pago efectuado el 19 de julio) (A.M.N.: LC. 1476-77, cuenta de gastos).

${ }_{28}$ Por ejemplo las reparaciones realizadas en el mes de abril de 1477 (A.M.N.: LC. 1476-77, cuenta de gastos). El sostenimiento de la burocracia concejil y el mantenimiento de las obras públicas se constituyeron en dos de las principales fuentes de gasto propiamente concejil a que tuvieron que hacer frente las haciendas municipales de la Corona de Castilla a finales de la Edad Media. Asi se constata en el caso de Haro (me remito a mi Tesis Doctoraf), y también ha sido puesto de manifiesto en otros núcleos urbanos (Carmen Fernández-Daza AlvEAR, La ciudad de Trujillo y su tierra... o.c., pp. 503-511, Manuel Fernando LAdero QueSADA, La ciudad de Zamora... o.c., pp. 247-255, Yolanda Guerrero Navarrete y José Maria Sánchez Benito, Cuenca en la Baja Edad Media... o.c., pp. 222-235, María Asenjo González, Segovia... o.c., pp. 467-468, Carmelo LU!S LOPEZ, La comunidad de villa y tierra de Piedrahita... o.c.. pp. 304-313, Juan Carlos MARTín CEA, El mundo rural castellano... o.c., pp. 233-234). La otra fuente principal del gasto, las costas jurídicas derivadas del aumento de los pleitos y litigios, no se constata en el Libro de Cuentas del concejo de Nájera de 1476-77. Sin embargo, éste debió de ser un ejercicio excepcional, puesto que en los otros dos Libros de Cuentas que se han conservado (1439-1440 y 1455-1456), especialmente en el segundo, los gastos jurídicos tuvieron un importante peso en la hacienda concejil. Los datos pueden verse en (A.M.N.: LC. 1455-56, cuenta de gastos).

${ }^{29}$ "A ocho dias del dicho mes (diciembre de 1476) fue la Conçepçión de la Virgen Maria del voto de la çibdad por la mortandad. Mandaron dar de comer a los pobres e raçiones a los enber- 
En cuanto a los gastos efectuados en grano, la proporción entre el trigo y la cebada fue favorable al trigo (un $92,2 \%$ del total del gasto, frente al $7,8 \%$ correspondiente a la cebada). La expensa de trigo se destinó este año fundamentalmente a la venta del mismo para la obtención de numerario. Los ingresos por la venta de este cereal, como ya hemos visto, también quedaban asentados en la cuenta de ingresos en dinero. A una distancia bastante mayor se situaban los gastos ocasionados en la concesión de presentes a la condesa, pago del salario al pregonero del concejo, comidas, la limosna concedida el día de la Concepción a pobres y envergonzados $y$, por último, se concedieron varias fanegas de trigo a dos personas, sin que se expliciten los motivos ${ }^{30}$. Respecto a los pagos en cebada, el monto total de las fanegas se destinó este año a la alimentación de las mulas, rocines y caballos que llevaban los mensajeros cuando iban a otras villas y ciudades.

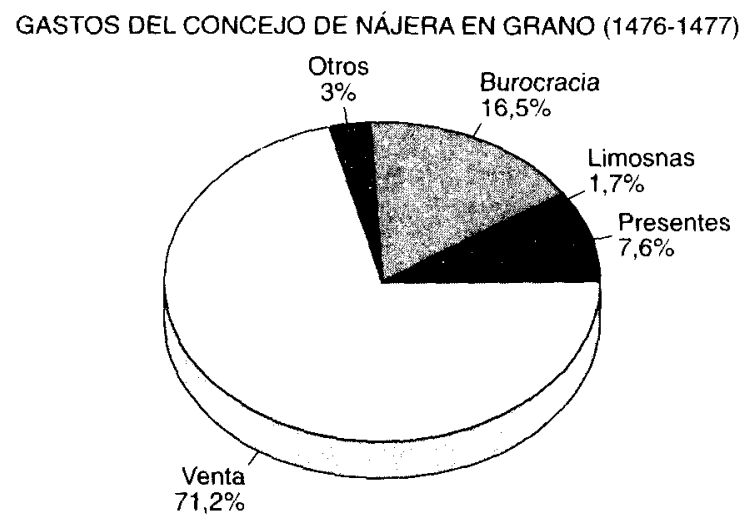

Nota: trigo y cebada

gonçados". En total, el bolsero Martín Romero gastó 665 maravedis (A.M.N.: LC. 1476-77, cuenta de gastos). El pago de "votos" también se constata en otros núcleos urbanos. El concejo de Paredes de Nava pagaba todos los años un "voto" a Santo Toribio de Liébana (Juan Carlos Martin CEA, El mundo rural castellano... o.c., p. 234).

${ }_{30}$ Gastos efectuados en el mes de diciembre de 1476 , y abril y mayo de 1477 (A.M.N.: LC. 1476-77, cuenta de gastos). El concejo de Haro también pagaba en especie (trigo) o de forma mixta, especie y dinero, a aigunos de los oficiales concejiles como el merino carcelero o el oficial. Este último desempeñaba las funciones de pregonero y verdugo (me remito a mi Tesis Doctoral). 


\section{LA INCIDENCIA DE LAS FISCALIDADES REAL Y SEÑORIAL}

Gracias a la diligencia del bolsero Martín Romero, que anotó parcialmente en su Libro los montos de maravedís recaudados en los «libros de cogechas", podemos establecer un balance bastante aproximativo sobre el peso e incidencia de las diferentes fiscalidades que entraban en juego en la ciudad de Nájera y en sus aldeas (ver cuadro n.. 4 , apend. estadístico). En cuanto a los impuestos reales, los que tuvieron el mayor peso en la contribución del ejercicio 1476-1477 fueron los servicios extraordinarios, recaudados en forma de monedas y pedidos ${ }^{31}$, así como los pagos a la Hermandad ${ }^{32}$, quedando relegada la martiniega a un papel secundario. Un tributo, la martiniega, que era detraído en parte por el alcaide de Nájera ${ }^{33}$. En cuanto a la fiscalidad señorial, el conde de Treviño demandó a la ciudad un pedido extraordinario o "emprestido" de cincuenta mil maravedís ${ }^{34}$. Pero, además, si tenemos en cuenta las cantidades gastadas por el concejo en concepto de presentes y servicios militares al señor (sueldos de peones y ballesteros), debemos de sumar a la cuantía del "emprestido" otros diez mil doscientos cincuenta y seis maravedís.

De acuerdo con los datos conservados (ver cuadros n. 22 y $n . .4$ del apend. estadístico), podemos comprobar cómo la capacidad detractora de las fiscalidades extraconcejiles (real y señorial) fue superior a la de la fiscalidad concejil. Una diferencia que podemos suponer que se dispararía

31 Estos servicios, que debian de ser otorgados en Cortes, fueron demandados por los monarcas castellanos a lo largo del siglo XV, sobre todo, durante las guerras contra los musulmanes granadinos (Miguel Ángel LADERO QUESADA, "Fiscalidad regia y génesis de Estado en la Corona de Castilla (1252-1504)", Espacio, Tiempo y Forma, Ha. Medieval, vol. n. 4 (1991), pp. 95-135, especialmente pp. 99-103).

32 Este año Nájera y sus aldeas contribuyeron con 20.650 maravedís al sostenimiento de la Hermandad. Pero, además, se repartió en la ciudad otro "pecho" para pagar "tres lanças de Hermandad", recaudándose otra cuantía de 22.000 maravedis (A.M.N.: LC. 1476-77, cuantias de los "Libros de Cogechas", folio inserto al inicio del Libro de Cuentas).

${ }_{33}$ "El libro de la martiniega de que fueron cogedores Valgannon e Ynnigo de Salsedo, montó quatro quiebras e malparado e derechos de cogedores e escrivano çinco mill e quatroçientos maravedís, más montó lo de Triçio de que fue cogedor Pedro de Sova el moço mill e veinte maravedis que son todos seys mill e quatroçientos e veynte maravedís. De estos dieron a Juan de Salinas (alcaide) dos mill e seisçientos que monta la cabeça de la martiniega por merçed que el tiene del rey...". La detracción de esta renta por parte de oficiales reales o particulares ya se venia produciendo en los territorios de la Corona de Castilla por lo menos desde mediados del siglo XIV (Julián Clemente RAMOS, "Fiscalidad real y renta feudal. La martiniega, la fonsadera y el yantar a mediados del siglo XIV en la Castilla de las merindades", Anuario de Estudios Medievales, vol. n. ${ }^{\circ}$ 22 (1992), pp. 767-784).

34 Estos "emprestidos" también fueron demandados en Paredes de Nava por sus señores, los Manrique, a lo largo del siglo XV. Como en Nájera, las contribuciones a este linaje fueron importantes (Juan Carlos MARTIN CEA, El mundo rural castellano... o.c., p. 236). 
aún más con los maravedis provenientes de la alcabala ${ }^{35}$. En lo referente a la presión fiscal sobre la población, el peso jugado por las fiscalidades real y señorial fue todavía más rotundo. El concejo sólo repartió un «pecho» para reparar el puente, que montó un total de diez mil seiscientos setenta y ocho maravedís, mientras que los repartimientos fiscales realizados en la ciudad y en las aldeas para pagar los impuestos reales y señoriales ascendieron a ciento cuarenta y cuatro mil doscientos treinta y seis maravedís. La presión fiscal proveniente de las imposiciones indirectas, alcabala fundamentalmente, no haria sino reforzar aún más el peso abrumador que las fiscalidades real y señorial ejercieron este año de 1477 sobre los pobladores de la jurisdicción de la ciudad de Nájera. Una jurisdicción en la que, como podemos comprobar en el cuadro n. 9 (apend. estadístico), el núcleo urbano fue el principal contribuyente (con un $84,3 \%$ ), a gran distancia de las aldeas, Tricio y Cenicero, en este orden (con un 15,6\%).

\section{CUANTIAS DE LOS "PECHOS" REALES Y SEÑORIALES REPARTIDOS EN NÁJERA (1476-1477)}

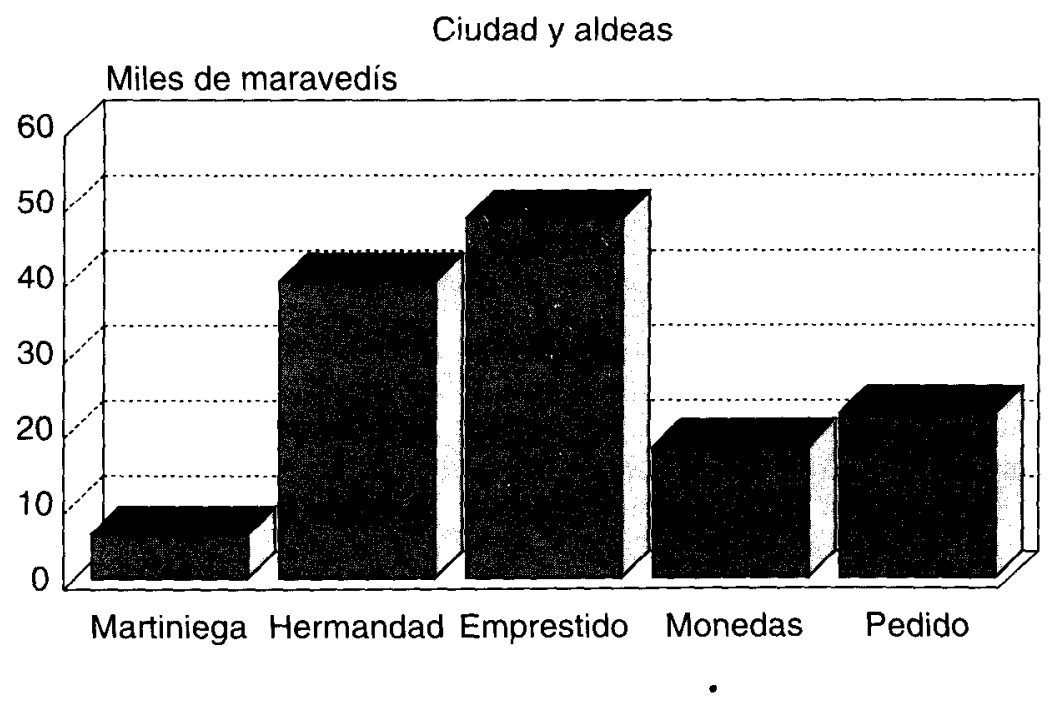

35 Desgraciadamente desconocemos la cuantía de este impuesto indirecto que, según Miguel Ángel LADERO QUESADA proporcionaba de un 70 a un $80 \%$ de los ingresos ordinarios obtenidos por la monarquía castellana en el siglo xV (Miguel Ángel LADERO QUESADA, "Instituciones fiscales y realidad social en el siglo xV castellano", El siglo XV en Castilla... o.c., pp. 58-88, especialmente p. 65). La importancia del impuesto de la alcabala en el marco fiscal municipal ha sido puesta de 


\section{CONCLUSIONES}

Con el análisis del Libro de Cuentas de 1476-1477 del bolsero Martín Romero, hemos pretendido obtener una primera cata o muestreo de la estructura de la hacienda concejil de Nájera a finales de la Edad Media. Ello nos ha permitido vislumbrar algunas de sus características que deberán de ser corroboradas en un estudio de mayor calado que pretendemos realizar más adelante. Las conclusiones obtenidas han sido las siguientes:

- Los ingresos y gastos de la hacienda concejil de Nájera se efectuaban en dinero y en grano (trigo y cebada), quedando claramente definidos en dos apartados del Libro de Cuentas.

- Las fuentes de financiación concejil de este año provinieron fundamentalmente de los ingresos ordinarios. Dentro de éstos, los propios constituian el principal recurso económico del concejo.

- El balance final del ejercicio 1476-77 fue positivo. Sin embargo, los recursos ordinarios no fueron suficientes para hacer frente al gasto concejil. De ahi que el concejo tuviera que recurrir a la venta de trigo y a la realización de un repartimiento fiscal para financiar la obra del puente de la ciudad.

- La percepción de las rentas de propios, tanto las provenientes de la explotación de derechos concejiles como las procedentes de la explotación de los bienes de propios, se realizaba mediante el arrendamiento de las mismas a particulares.

- El mantenimiento de la burocracia y las obras públicas constituyeron por este orden las dos principales fuentes de gasto concejil.

- El concejo intervenía en la percepción de los tributos reales y señoriales. Para ello nombraba "cogedores", encargados de recaudar los "pechos" repartidos en la ciudad y en las aldeas para sufragar los tributos del Rey y del señor. De ahí que el bolsero Martín Romero asiente en su Libro los ingresos y gastos derivados de las fiscalidades extraconcejiles.

manifiesto por José María Monsalvo Antón y por José Ignacio Moreno Núñez (José Maria Monsalvo ANTón, El sistema político concejii... o.c., pp. 364-377, José Ignacio Moreno NúñEz, Avila y su tierra.. o.c., pp. 229-243). Por otro lado, desconocemos si el conde de Treviño detraía este impuesto, en parte o totalmente, en su propio beneficio. Tal y como a puesto de manifiesto Miguel Ángel LADERO QUESADA, el paso a la jurisdicción señorial de un gran número de núcleos urbanos de la Corona de Castilla a lo largo del siglo XV, permitió a la nobleza enajenar en su faver rentas reales, especialmente la alcabala (Miguel Ángel LADERO QUESADA, "Fiscalidad regia... O.C., pp. 107-110 y "Rentas condales de Plasencia... o.c., pp. 168-190). En Haro, los Velasco, señores de la villa, participaron activamente en la recaudación de este impuesto en la segunda mitad del siglo XV (me remito a mi Tesis Doctoral). 
- La capacidad fiscal detractora conjunta de las instancias políticas superiores, monarquía y señorío, fue en este ejercicio bastante superior a la del concejo, incidiendo además esta fiscalidad extraconcejil de forma directa sobre los pobladores de la ciudad y de las aldeas.

- El núcleo urbano del alfoz, Nájera, fue el principal centro contribuyente, a gran distancia de las aldeas de Tricio y Cenicero. Podemos deducir, por consiguiente, que el mayor porcentaje de población del alfoz se concentraba dentro de las murallas de la ciudad y en sus arrabales.

\section{APÉNDICE ESTADÍSTICO}

Cuadro $n .^{\circ}$ 1. Derechos percibidos por el concejo de Nájera en el ejercicio 1476-1477 en concepto de rentas de propios

\begin{tabular}{lc}
\hline \multicolumn{1}{c}{ Rentas } & Importe (maravedís) \\
\hline Gallinero & 4.500 \\
Sisa de la Carnicería & 3.900 \\
Najerilla & 3.750 \\
Campos Alvos & 3.500 \\
Aver del Peso & 3.000 \\
Trujal & 2.000 \\
Juradería & 2.000 \\
Herbaje de Alesón & 1.600 \\
Escribanía & 1.000 \\
Custierazgo de los Valles & 1.000 \\
Correduría & 600 \\
Sobrecustierazgo de los Valles & 600 \\
Botica & 550 \\
Cuevas y Palomas & 420 \\
Ríos y Caminos & 300 \\
Matarredo y Divisas de Majarres & 300 \\
Viñas de Cenicero & 300 \\
Ejidos & 250 \\
Tasa del Limosnero & 150 \\
Peaje del Puente & 150 \\
Tasa de la Abadía & 130 \\
Derecho de los vecinos de Cenicero & 100 \\
Tasa del Monasterio de Cañas & 80 \\
Porteria & 10 \\
Parra & 19.191 \\
Total & \\
\hline & \\
&
\end{tabular}


Cuadro $n .^{\circ} 2$ Ingresos del concejo de Nájera en el ejercicio 1476-1477 (en dinero y grano)

Metálico

\begin{tabular}{lc}
\hline \multicolumn{1}{c}{ Procedencia } & Cuantía (maravedís) \\
\hline Propios & 55.841 \\
Penas & 1.250 \\
Repartimientos fiscales concejiles & 10.678 \\
Otros ingresos & 600 \\
Repartimientos fiscales extraconcejiles & 49.406 \\
Total & 117.775 \\
\hline
\end{tabular}

Trigo

\begin{tabular}{lc}
\hline \multicolumn{1}{c}{ Procedencia } & Cuantía (fanegas) \\
\hline Molinos & 220 \\
Heredades y Solares & 84 \\
Total & 304 \\
\hline
\end{tabular}

Cebada

\begin{tabular}{|c|c|}
\hline Procedencia & Cuantía (fanegas) \\
\hline Heredades y Solares & 84 \\
\hline Total & 84 \\
\hline
\end{tabular}

Cuadro n. ${ }^{\circ}$ 3. Gastos efectuados por el concejo de Nájera en el ejercicio 1476-1477 (en dinero y grano)

Metálico

\begin{tabular}{lc}
\hline \multicolumn{1}{c}{ Destino } & Cuantía (maravedís) \\
\hline Haciendas Real y Señorial & 45.003 \\
Burocracia & $25.163,5$ \\
Obras públicas & 24.377 \\
Otros gastos & 6.682 \\
Total & $101.225,5$ \\
\hline
\end{tabular}


Trigo

\begin{tabular}{lc}
\hline \multicolumn{1}{c}{ Destino } & Cuantia (fanegas) \\
\hline Venta & 168 \\
Presentes señoriales (a la condesa) & 18 \\
Limosnas (pobres y envergonzados) & 4 \\
Oficiales concejiles (pregonero) & 12 \\
Comidas & 8,5 \\
Otros & 7 \\
Total & 217,5 \\
\hline
\end{tabular}

Cebada

\begin{tabular}{lc}
\hline \multicolumn{1}{c}{ Destino } & Cuantía (fanegas) \\
\hline Alimento de bestias de silla & 18,5 \\
Total & 18,5 \\
\hline
\end{tabular}

Cuadro n. ${ }^{\circ}$ 4. Cuantías de los repartimientos reales y señoriales recaudados en la ciudad de Nájera y en sus aldeas de Tricio y Cenicero en el ejercicio 1476-1477 (en maravedís)

\begin{tabular}{lcrrrrr}
\hline & Martiniega & Hermandad & Emprestido & Monedas & Pedido & \multicolumn{1}{c}{ Total } \\
\hline Nájera & 5.400 & 37.900 & 38.000 & 15.140 & 25.221 & 121.661 \\
Tricio & 1.020 & 3.250 & 8.000 & 4.805 & & 17.075 \\
Cenicero & & 1.500 & 4.000 & & & 5.500 \\
Total & 6.420 & 42.650 & 50.000 & 19.945 & 25.221 & 144.236 \\
\hline
\end{tabular}

